\title{
Three Different Approaches to the Inferior Mesenteric Artery during Robotic D3 Lymphadenectomy for Rectal Cancer
}

\author{
Songphol Malakorn, $\mathrm{MD}^{1,2}$, Tarik Sammour, MBChB, $\mathrm{PhD}^{1}$, Brian Bednarski, $\mathrm{MD}^{1}$, Yi-Qian Nancy You, $\mathrm{MD}^{1}$, and \\ George J. Chang, MD, MS ${ }^{1}$ \\ ${ }^{1}$ Division of Surgery, Department of Surgical Oncology, The University of Texas MD Anderson Cancer Center, Houston, \\ TX; ${ }^{2}$ Colorectal Division, Department of Surgery, Chulalongkorn University, Bangkok, Thailand
}

\begin{abstract}
Background. In rectal cancer surgery, proximal ligation of the inferior mesenteric artery (IMA) with radical lymphadenectomy is the accepted standard of care. ${ }^{1}$ Our purpose is to describe three different standardized technical approaches for the management of the IMA during D3 lymphadenectomy. ${ }^{2}$

Methods. Operative videos of three robotic D3 lymphadenectomy procedures for rectal cancer were reviewed and annotated with schematic anatomical descriptions for clarification.

Results. There are three methods for the management of the IMA during D3 lymphadenectomy for rectal cancer. Standard high ligation is technically the simplest to perform and provides excellent mesenteric length but relies solely on marginal vessel blood supply from the middle colic artery. ${ }^{3}$ Low ligation with ascending left colic artery preservation is more complex technically but affords excellent vascular supply due to preservation of IMA blood flow, while potentially limiting mesenteric length. ${ }^{4}$ The central vascular sparing technique is the most complex to perform but allows excellent mesenteric length due to the presence of two separate points of mesenteric division, while also potentially improving blood supply due to decreased vascular resistance and improved collateralization. With each technique, central ligation of the inferior
\end{abstract}

Electronic supplementary material The online version of this article (doi:10.1245/s10434-017-5792-8) contains supplementary material, which is available to authorized users.

(C) Society of Surgical Oncology 2017

First Received: 5 December 2016;

Published Online: 17 February 2017

G. J. Chang, MD, MS

e-mail: gchang@mdanderson.org mesenteric vein above the splenic flexure tributary is performed to release the mesentery.

Conclusions. The three methods to manage the IMA vary in their technical complexity, preservation of colonic conduit blood supply, and provision of mesenteric length, with associated advantages and disadvantages. The choice of technique is dependent on anatomical and oncological considerations.

AUTHORS CONTRIBUTION All authors made substantial contributions to: conception, design, acquisition of data, analysis and interpretation of data; drafting the article and revising it critically for important intellectual content; and gave final approval of the version to be published.

CONFLICT OF INTEREST The authors have no conflict of interest to declare.

\section{REFERENCES}

1. Sammour T, Malakorn S, Bednarski BK, et al. Oncological outcomes after robotic proctectomy for rectal cancer: analysis of a prospective database. Ann Surg. 2016 (Epub ahead of print).

2. Watanabe T, Itabashi M, Shimada Y, et al. Japanese Society for Cancer of the Colon and Rectum (JSCCR) Guidelines 2014 for treatment of colorectal cancer. Int J Clin Oncol. 2015;20(2): 207-39.

3. Komen N, Slieker J, de Kort P, et al. High tie versus low tie in rectal surgery: comparison of anastomotic perfusion. Int $J$ Colorectal Dis. 2011;26(8):1075-8.

4. Bonnet S, Berger A, Hentati N, et al. High tie versus low tie vascular ligation of the inferior mesenteric artery in colorectal cancer surgery: impact on the gain in colon length and implications on the feasibility of anastomoses. Dis Colon Rectum. 2012;55: 515-21. 